\title{
DIFFERENCES IN MECHANISMS OF SOCIAL INTERACTION OF GIFTED CHILDREN BASED ON PEER ACCEPTANCE
}

\author{
DIFERENCIAS EN MECANISMOS DE \\ INTERACCIÓN SOCIAL EN NIÑOS DE ALTAS \\ CAPACIDADES EN FUNCIÓN DE LA \\ ACEPTACIÓN SOCIAL
}

\author{
PABLO HERNÁNDEZ-LASTIRI ${ }^{1}$, ÁFRICA BORGES ${ }^{1}$, \\ AND MARÍA CADENAS ${ }^{1,2}$
}

Cómo referenciar este artículo/How to reference this article:

Hernández-Lastiri, P., Borges, A.y Cardenas, M. (2019). Differences in Mechanisms of Social Interaction of Gifted Children Based on Peer Acceptance [Diferencias en mecanismos de interacción social en niños de altas capacidades en función de la aceptación social]. Acción Psicológica, 16(1), 13-30. https://doi.org/10.5944/ap.16.1.22169

\begin{abstract}
Early relationships with equals are considered a relevant factor in people's development. In order to study social interaction, Santoyo $(1996,2006)$ proposes the functional mechanisms of social effectiveness, social responsiveness, and reciprocity. To analyze and compare these mechanisms in the participants of the Comprehensive Program for High Abilities (CPHA) with the purpose of
\end{abstract}

detecting possible differences between the students who are better considered by their equals and those who have less social acceptance. The sample was selected by a sociogram, and the social interaction was measured with the Observational Protocol for Interactions within the Classroom-OPINTEC, v.5 (Cadenas \& Borges, 2016, 2017; Cadenas, Borges, \& Falcón, 2013). The participants show effectiveness and correspondence, but they don't show social reciprocity. No differences were observed between the most valued ones and the most rejected ones.

Correspondence address [Dirección para correspondencia]: Pablo Hernández-Lastiri. Universidad de La Laguna, Spain.

Email: alu0100787337@ull.edu.es

ORCID: Pablo Hernández Lastiri (http://orcid.org/0000-0002-5953-7529), África Borges (http://orcid.org/0000-00018267-4401) y María Cadenas (http://orcid.org/0000-0002-3286-7093).

1Universidad de La Laguna, Spain.

2Universidad Europea de Canarias, Spain.

Retrieved: June 01, 2018.

Accepted: August 24, 2018. 
Observation represents and appropriate methodology for the studying of social relations in natural settings in combination with other procedures.

Keywords: High ability; Social interaction; Observation.

\section{Resumen}

Las relaciones tempranas con los iguales se consideran un factor relevante en el desarrollo de las personas. Para el estudio de la interacción social, Santoyo $(1996,2006)$ propone los mecanismos funcionales de efectividad, correspondencia y reciprocidad social. Analizar y comparar los mecanismos que regulan la interacción social en alumnado participante del Programa Integral para Altas Capacidades (PIPAC) con el fin de detectar posibles diferencias entre aquellos mejor considerados por sus pares y los que presentan una menor aceptación social. La muestra se selecciona mediante el sociograma y la interacción social se mide a través del instrumento de observación Protocolo de Observación de Interacción en el Aula-PINTA, v.5 (Cadenas \& Borges, 2016, 2017; Cadenas et al., 2013). Tanto los estudiantes focales más valorados como los más rechazados muestran patrones indicadores de presencia de efectividad y correspondencia social, pero no reciprocidad social. No se observaron diferencias entre ambos grupos. La observación representa una metodología adecuada para el estudio de relaciones sociales en ambientes naturales en combinación con otros procedimientos.

Palabras clave: Altas capacidades; Interacción social; Observación.

\section{Introduction}

The study of intelligence and the most talented ones goes back to the beginning of Scientific Psychology (Borges \& Hernández-Jorge, 2006). This early interest was followed by a long researcher tradition (see for example Gagné, 2015; Renzulli \& Reis, 2003; Tannenbaum 1986; Sternberg, 2000; Ziegler \& Phillipson, 2012) still has not got a universal definition of high ability and either of the problems that can concern this student body (for more information consult Plucker \& Callahan 2014; Subotnik, Olszewski-Kubilius, \& Worrel, 2011).

Several studies carried out within gifted education had focused in cognitive and different educational aspects like identification, self-learning, motivation, academic achievement, curriculum, etc. (see Almeida, Araújo, Sainz-Gómez, \& Prieto, 2016; Calero, García-Martin, \& Robles, 2011; Clinkenbeard, 2012; Little, 2012; Reis \& Renzulli, 2010; Sternberg, 2010; Stoeger \& Ziegler, 2010). Nevertheless the socio-emotional area had also received a great relevance being one of the most controversial areas within this field, with studies supporting the hypothesis of a positive personal and social adjustment of these students (Borges, Hernández-Jorge, \& Rodríguez-Naveiras, 2011; Hoogeveen, van Hell, \& Verhoeven, 2012; Jen, Gentry, \& Moon, 2017; López \& Sotillo, 2009; Neihart, 2007; Robinson, 2008) while others highlight that it is necessary to pay attention to the socio-emotional needs of these students, since some children could be more vulnerable in different aspects of their development (Coleman \& Cross, 2000; VanTasselBaska, 2009) and experience difficulties with their environment (Lee, Olszewski-Kubilius, \& Turner, 2012).

According to Coleman (2014a) the social context in the educational environments, like enrichment programs, is of absolutely relevance. Therefore, it is important to use the appropriate procedures to analyse the conduct in its natural environment. In the educational context several tools can be used to gather information about the social context or the social relations established within the classroom. In this study, we will focus on the sociogram and observation. The first one, the sociogram, is used to analyze the formal and informal organization of a group through the elections and rejections from each of the members that conform a group (Rodríguez \& Morera, 2001). Traditionally, this technique is based on the strategy of nomination by peers (children are asked to mention in order of preference those classmates they prefer for specific activities or who are their best friends). This strategy it is useful to identify the social status of a person within a group and to study social connections, but it has some limitations (see Santoyo, 1994b), for example, the restriction 
of nominating a limited number of children, or the fact that it gives information about the relations established but not the factors involved in the origin of those connections (Santoyo, 1994b). A possible solution is to use another procedure, the observation, in combination with the information offered by a sociogram (Santoyo, 1994b). Observation is one of the most recommended procedures for measuring social conducts, considering that it allows an objective study of behaviors at natural settings (Anguera, 1990; Anguera \& Hernández-Mendo, 2013), as it also provides great information.

In the field of gifted education, it is possible to find studies which used observation as a procedure to analyze certain aspects of the educational context. However, they are mainly focus in the figure of the teacher and his/her performance in the classroom or in academic aspects (see for example Cavilla, 2017; Coleman, 2014b; Graffram, 2006; McCoach, Rambo, \& Welsh, 2013; Mills, 2003; Netz, 2014; Westberg, Archambault, Dobyns, \& Salvin, 1993). To the best of our knowledge, only a few studies utilized observation in combination with other procedures to explore the social competence of gifted students (see Bokkina, 2016; Cadenas \& Borges, 2017; De Jonge, 2016) finding, in general terms, appropriate and adjusted behaviours within the classroom. The utility of studies settled at natural settings or the use of observation as an additional measure has been already indicated (see Coleman, 2014b; Lee, Olszewski-Kubilius \& Turner, 2012).

The study of social interaction must take into account the different variables which could affect the nature of the conduct and its manifestation (see Cairns, 1979; Santoyo, 1994a). In order to operativize social interaction, Santoyo (1996, 2006; see also Flores \& Santoyo, 2009) proposes three functional mechanisms that regulate it. Briefly, (a) social effectiveness, the ability of an individual to produce a reaction on the others; (b) social correspondence, to answer interactions from the environment, and (c) social reciprocity, bidirectional interaction between at least two individuals (see also Bakeman \& Gottman, 1989).

Thus, the aim of this study is to compare the functional mechanisms in order to check whether there are differences between the participants that are the most valued and those that are the most rejected by their peers. It may be hypothesized that those students who were most valued for working and playing would show a better performance of social effectiveness, correspondence and reciprocity in relation to the most rejected ones. If this hypothesis is correct, it is expected to find significant behavioral patterns indicators of presence of these mechanisms and no significant patterns indicators of absence of social effectiveness, correspondence and reciprocity on the most valued students.

\section{Method}

\section{Methodology and design}

Observational methodology was employed, with a multidimensional, ideographic and punctual design (Anguera, Blanco, \& Losada, 2001).

\section{Participants}

\section{Sample description}

The participants of this study belong to the level of age between 9 and 12 years old from the Comprehensive Program for High Abilities (CPHA), University of La Laguna. At the beginning of this study, the group was composed by seven children (four boys and three girls). The sociogram was applied to this group at the beginning of the second trimester. During the development of the program, four new participants joined the group (two girls and two boys). In total, the group who participated in the observational study was composed by eleven children (five girls and six boys) diagnosed with high intellectual abilities.

\section{Observed participants}

On this study the interaction is analyzed through three agents: focal student, peers and educators. Briefly, the focal student is the participant who is observed; the peers, the rest of the classmates present in the classroom and the educators, the teacher or instructor present in the class- 
room (Cadenas \& Borges, 2016, 2017; Cadenas et al., 2013).

Focal students: Four students, labeled as focal students, were selected based on the social status to analyze their interaction with the group. They were two boys and two girls of 9 years old considered: (a) the most valued for working-MVW; (b) the most valued for playing-MVP; (c) the most rejected for working-MRW; and (d) the most rejected for playing-MRP. These labels were used after the analysis of the sociogram. Since the MRW student got the highest number of rejections, both in playing and working, the next most rejected student for playing, without any other condition allocated, was selected with the aim of coding four different students.

Although the group is made up of boys and girls, given its small size, in this research it is employed only the male gender when the focal students are referred in order to guarantee the data's confidentiality.

Classmates: Those students that were not selected as focal students. The group is composed by four boys and three girls, from 9 to 12 years old. Additionally, when a focal student is being observed, the other three focal students were included in the group of classmates.

Educators: The instructors of the group: a 33 years old psychologist with a Master Degree and five years of experience in the program, and a 21 years old student of Psychology with two years of experience.

Observers: The observers were the author of this study and a 23 years old Master student. The observers were trained with a standardized procedure (Cadenas, Rodríguez, \& Díaz, 2012).

\section{Instruments}

\section{Sociogram}

It was employed for selecting the focal students. The students had to choose or reject a maximum of three classmates, in order of preference, for working in some activity or for playing. As sample questions, it was asked "If the teacher asks you to choose three classmates for working in an activity, which three classmates would you choose/would you not choose?" or "If the teacher asks you to choose three classmates for playing, which three classmates would you choose/would you not choose?"

\section{Observational instrument}

The fifth version of the Observational Protocol for Interactions within the Classroom (OPINTEC, v.5; Cadenas $\&$ Borges, 2016) was used. The description of this instrument has been already published (Cadenas \& Borges, 2016, 2017; Cadenas et al., 2013). Briefly, the instrument is based on the functional mechanisms that regulate social interaction (effectiveness, correspondence and social reciprocity) proposed by Santoyo $(1996,2006)$ and it is designed to observe social interaction in natural educational contexts. It is hierarchically structured in five macrocategories, collecting six criteria, deployed in 14 codes that catch interaction behaviors of three agents: focal student, classmates and instructors, differentiating between cognitive and socioaffective tasks. It assesses three types of interaction: positive, negative and absence of interaction (Cadenas et al., 2013; Cadenas \& Borges, 2016, 2017). The psychometric properties of the fifth version of this instrument, in terms reliability and homogeneity, have been previously published (Cadenas \& Borges, 2016). Briefly, the levels of reliability achieved the standard of 0.90 for Generalizability Theory-GT (Salvia, Ysselydke, \& Bolt, quoted in Briesch, Swaminathan, Welsh, \& Chafouleas, 2014). The homogeneity of the categories, analyzed through GT, also reached the values recommended in literature 0.0 (see Castellano, HernándezMendo, Gómez, Fontetxa, \& Bueno, 2000). The cross validity of the instrument is also confirmed (Bokkina, 2016; Cadenas \& Borges, 2016; De Jonge, 2016).

The instrument's structure is given in the Table 1.

\section{Recording and coding instruments}

The observations were recorded with videocameras SONY DCR-SR58E. The behaviors' coding was done by the software Lince (Gabín, Camerino, Anguera, \& Castañer, 2012). 
Table 1.

Observation Protocol for Interactions within the Classroom (OPINTEC-v.5).

\begin{tabular}{|c|c|c|c|c|}
\hline Macro Category & Standard & Code & Agent & Type of activity \\
\hline Positive Social & Activity-Related & SI: Starts Interaction & T: Teacher & \multirow{11}{*}{$\begin{array}{l}\text { W: Work } \\
\text { WI: Individual } \\
\text { Work activity } \\
\text { WG: Grupal Work } \\
\text { Activity }\end{array}$} \\
\hline \multirow[t]{10}{*}{ Interaction } & interactions & A: Answers & F: Focal Student & \\
\hline & & & C: Classmate & \\
\hline & & Cl: Collective Interaction & F: Focal Student & \\
\hline & \multirow{7}{*}{$\begin{array}{l}\text { Non-related with the } \\
\text { activity interactions }\end{array}$} & & C: Classmate & \\
\hline & & SGI: Starts General & T: Teacher & \\
\hline & & Interaction & F: Focal Student & \\
\hline & & AGI: Answers General & C: Classmate & \\
\hline & & Interaction & & \\
\hline & & FD: Fondness & F: Focal Student & \\
\hline & & & C: Classmate & \\
\hline \multirow{3}{*}{$\begin{array}{l}\text { Negative Social } \\
\text { Interaction }\end{array}$} & Negative Interaction & AP: Assaults Physically & F: Focal Student & \multirow{7}{*}{$\begin{array}{l}\text { PI: Individual } \\
\text { Playful activity } \\
\text { PG: Grupal Playful } \\
\text { Activity }\end{array}$} \\
\hline & & AV: Assaults verbally & C: Classmate & \\
\hline & & DA: Disruption & F: Focal Student & \\
\hline Absence Interaction & Absence Interaction & NI: No interaction & F: Focal Student & \\
\hline Conducts of the & Exposition in groups & EG: Exposition in groups & T: Teacher & \\
\hline Educational Agent & Contingency & $\begin{array}{l}\text { RF: Reinforcement } \\
\text { CL: Control }\end{array}$ & & \\
\hline \multicolumn{2}{|c|}{ Instrumental Categories } & Y: Unobservable & F: Focal Student & \\
\hline
\end{tabular}

Note. Retrieved from Cadenas and Borges (2016, p. 60).

\section{Procedure}

This study was carried out in an out of school enrichment program for gifted students, The Comprehensive Program for High Abilities (CPHA), University of La Laguna. This program started in 2004 to attend the socio-affective needs of the students with high abilities and their families. It is structured in different groups attending to the age of the participants with two educators in each level. The sessions take place every two weeks and the program lasts from October to June, divided in three trimesters (Borges \& Hernández-Jorge, 2006). All the sessions are recorded with video cameras for research and intervention proposes, with the authorization of the participating families.

The first step was to apply a sociogram (Rodríguez \& Morera, 2001) to objectively select the focal students who were going to be individually observed. In particular, the aim was to identify those who were most valued and re- jected by their peers for working and sharing their spare time. The sociogram was applied in January and not at the beginning of the course for several reasons: (1) the families can join the program along the school year, so new participants can get into the group; (2) the sessions take place every two weeks, therefore the participants need more time to know each other; (3) although the majority of the students have participated in previous editions of the program, not all of them were allocated in the same group. Once the focal students were classified using the sociogram, the sessions for coding were selected. Two sessions were chosen for each focal student in order to guarantee a higher representation of the observed behaviors, dismissing the three first sessions with the aim of avoiding the reactivity bias, known as the change in our behavior as a consequence of being observed and/or evaluated (Behar \& Riba, 1993), as well as those ones in which the visibility of the focal student were not appropriate. The sessions to observe each focal student were selected attending to: at- 
Table 2.

Selected sessions for each focal student.

\begin{tabular}{l} 
Focal student \\
\hline Most valued for working (MVW) \\
Most valued for playing (MVP) \\
Most rejected for playing (MRP) \\
Most rejected for working (MRW) \\
\hline
\end{tabular}

tendance of the sample, suitable visibility of focal students and appropriate sound quality. The sessions selected for each student are in Table 2

The MRW student started in the program in the third month of the academic year, and for this reason, it was decided to choose later sessions. With the purpose of knowing the minimum required time for extracting a representative sample of behaviors for each focal student and the number of sessions (Blanco-Villaseñor, 1991; RodríguezDorta \& Borges, 2016, 2017) Generalizability Theory was used (GT, Cronbach, Gleser, Nanda, \& Rajaratnam, 1972). Although in the case of the most valued for working (MVW), by coding only the 20 minutes extracted with a Decision Study, a limited number of patterns were obtained. This is why it was necessary to use the saturation principle (Rodríguez-Dorta \& Borges, 2016), increasing the coding time.

\section{Data analysis}

The sociogram was analyzed following the procedure indicated by Rodríguez and Morera (2001). Due to the group characteristics and the limited number of students SER (sum of received elections) and SRR (sum of received rejections) indexes were used. This was considered the most adequate way to measure popularity in this study since SER and SRR are indicators of the position in which a child is selected by their peers. The procedure to calculate these indexes is the following: the participants were asked to write down three names in order of priority. The first position is scored with 3 points, the second with 2 points and the third one with 1 point. That means a child who is nominated in the first place by four children will have a higher score (in SER or SRR) than another one who has been nominated in first place by two of his or her peers. All the sociograms were analyzed according to this procedure and those who had the higher scores in each cat-
Sessions

$25^{\text {th }}$ of November of 2014 and $10^{\text {th }}$ of February of 2015

$25^{\text {th }}$ of November of 2014 and $10^{\text {th }}$ of February of 2015

$25^{\text {th }}$ of November of 2014 and $24^{\text {th }}$ of February of 2015

$27^{\text {th }}$ of January and $21^{\text {st }}$ of April of 2015

egory (most popular for working, most popular for playing, most rejected for working and most rejected for playing) were selected as focal students. For more information, check Rodríguez and Morera (2001).

The calculation of the interobserver reliability was done by the index Kappa of Cohen (1960), with the program SPSS, v21 and the GT (Cronbach et al., 1972) with the program SAGT v1.0. (Hernández-Mendo, Ramos-Pérez, \& Pastrana, 2012). The Decision Study for the coding time and the number of sessions to observe for each focal student was done through GT, with the same program.

For the detection of behavioral patterns that operativize the interaction mechanisms, lag sequential analysis of Bakeman and Quera (1996) was used. This analysis consists in detecting associations between a precedent and a consequent behavior, explaining the interaction strength by the adjusted residuals, that are considered significant with values over 1.96 (Bakeman \& Quera, 1995). In order to determine the relationship of the behaviors included in the pattern, the association coefficient Q of Yule was also calculated (Yule \& Kendall, 1957; quoted in Lloyd, Kennedy, \& Yoder, 2013). Both analysis were done through the program SDIS-GSEQ v.5.1. (Bakeman \& Quera, 1996). Additionally, the $d$ of Cohen was calculated to determine the effect size (Cohen, 1988).

The operationalization of the functional mechanisms of interaction identified by Santoyo $(1996,2006)$ was done following the behavioral patterns identified by Cadenas and Borges (2016) based on their definition. The employed criterion for the selection of precedent behaviors was a relative frequency equal or higher than 0,02 (Rodríguez-Naveiras, 2011), which allows us to reject low frequency behaviors that could give rise to insufficiently representative patterns of the behavioral universe of focal 
students. Those antecedents which are below this criterion are not calculated and are labeled as do not apply-N.A.

\section{Results}

The results are presented as follows: firstly, the sociogram. Secondly, those related with the observation, where the results of reliability analysis are presented, followed by the Decision Study, after that, the relative frequencies of behaviors, concluding with the sequential analysis.

\section{Sociogram results}

The results of SER and SRR when questions of sociogram are related with working are shown in Table 3.

Table 3.

SER and SRR values for working.

\begin{tabular}{lrrrrrrr}
\hline Students & $\mathbf{1}$ & $\mathbf{2}$ & $\mathbf{3}$ & $\mathbf{4}$ & $\mathbf{5}$ & $\mathbf{6}$ & $\mathbf{7}$ \\
\hline Student 1 & & 3 & $\underline{3}$ & & $\frac{2}{2}$ & 2 & 1 \\
Student 2 & 3 & & $\underline{2}$ & $\frac{3}{1}$ & 2 & 1 & \\
Student 3 & & 3 & & & 1 & 2 & $\frac{3}{3}$ \\
Student 4 & & 3 & 2 & & & & $\frac{3}{2}$ \\
Student 5 & $\underline{2}$ & 1 & $\underline{3}$ & 3 & & & 1 \\
Student 6 & 3 & 2 & $\underline{3}$ & & & & \\
Student 7 & 3 & 2 & $\underline{2}$ & $\underline{3}$ & 1 & $\underline{1}$ & \\
\hline SER & 9 & $\mathbf{1 4}$ & 2 & 4 & 6 & 3 & 4 \\
\hline SRR & 2 & 0 & $\mathbf{1 3}$ & 6 & 2 & 5 & 6 \\
\hline
\end{tabular}

Note. Numbers underlined f.e 3 represents nominations in negative.

Those related with playing are shown in Table 4 .

Table 4

SER and SRR values for playing.

\begin{tabular}{lccccccc}
\hline Students & $\mathbf{1}$ & $\mathbf{2}$ & $\mathbf{3}$ & $\mathbf{4}$ & $\mathbf{5}$ & $\mathbf{6}$ & $\mathbf{7}$ \\
\hline Student 1 & & 3 & $\underline{3}$ & & $\underline{2}$ & 2 & 1 \\
Student 2 & 3 & & $\underline{3}$ & 1 & $\underline{2}$ & $\frac{1}{2}$ & 2 \\
Student 3 & & $\underline{3}$ & & 3 & 2 & $\underline{2}$ & 1 \\
Student 4 & & $\underline{3}$ & 3 & & 2 & $\underline{2}$ & 1 \\
Student 5 & $\underline{3}$ & $\underline{2}$ & 2 & 3 & & & 1 \\
Student 6 & 1 & 3 & $\underline{3}$ & & & & 2 \\
Student 7 & & 1 & $\underline{3}$ & 2 & 3 & $\underline{2}$ & \\
\hline SER & 4 & 7 & 5 & $\mathbf{9}$ & 7 & 2 & 8 \\
\hline SRR & 3 & 8 & 12 & 0 & 4 & $\mathbf{7}$ & 0 \\
\hline
\end{tabular}

Note. Numbers underlined f.e 3 represents nominations in negative.
Those who are identified as focal students are in bold. Student 3 obtained the highest value in SER (14) for working, while student 2 scored the highest in SRR (13). For playing, student 4 was the most valued (9) and student 6 was considered the most rejected (7). Students 3 and 2 had higher values in SRR, however they had another condition allocated. The aim of this study was to identify different students, so it was necessary to classify student 6 as MRP.

\section{Interobserver reliability analysis}

It was calculated through the coefficient of Kappa of Cohen (1960) and the GT (Cronbach et al., 1972), following a uni-facet design $\mathrm{CxO}$, Codes $(\mathrm{C})$ with 33 levels, and Observers $(\mathrm{O})$ with two. The measurement plan was $\mathrm{C} / \mathrm{O}$, where the generalized facet was Observers.

In a first analysis, both coefficients were under the criterion (Fleiss, 1981; quoted in Bakeman y Gottman, 1989; Volpe, Briesch \& Gadow, 2011), for this reason, new reliability sessions were necessary. In a second session, the values exceeded the Kappa criterion, but not in GT, taking place a third session when both indices obtained appropriate values (Table 5).

Table 5.

Kappa and GT indexes, Uni-facet Crossover Design OxC. Random Estimation Plan. Measurement Plan C/O.

\begin{tabular}{llll}
\hline \multirow{2}{*}{ Sessions } & \multirow{2}{*}{ Kappa } & \multicolumn{2}{c}{ GT } \\
\cline { 3 - 4 } & & Relative & Absolute \\
\hline $1^{\circ}$ & .504 & .647 & .614 \\
$2^{\circ}$ & .879 & .747 & .747 \\
$3^{\circ}$ & .879 & .859 & .859 \\
\hline
\end{tabular}

\section{Decision Study for time of observation}

The analysis carried out through an uni-facet design CxT, with 33 levels for the facet Codes (C) and three for Periods of Time (T). The measurement plan is $\mathrm{C} / \mathrm{T}$, where the generalized facet is Periods of time. The results, both the generalizability study and the Decision Study, are shown for each focal student in Table 6 . 
Table 6.

Decision Study for Time.

\begin{tabular}{lcccccc}
\hline & \multicolumn{2}{c}{ Generalizability Study } & \multicolumn{5}{c}{ Decision Study } \\
\hline $\begin{array}{l}\text { Focal } \\
\text { Student }\end{array}$ & $\begin{array}{c}\text { Time } \\
\text { Periods }\end{array}$ & G Relative & G Absolute & $\begin{array}{c}\text { Time } \\
\text { Periods }\end{array}$ & G Relative & G Absolute \\
\hline MVW & 3 & .890 & .890 & 4 & .920 & .920 \\
MVP & 3 & .798 & .798 & 7 & .902 & .902 \\
MRP & 3 & .741 & .741 & 10 & .905 & .905 \\
MRW & 3 & .750 & .741 & 10 & .909 & .905 \\
\hline
\end{tabular}

Note: MVW: Most valued for working. MVP: Most valued for playing. MRP: Most rejected for playing. MRW: Most rejected for working.

\section{Decision Study for sessions}

The analysis was made through an uni-facet design $\mathrm{CxS}$, with 33 levels for the facet Codes (C) and two for Sessions (S). The measurement plan is $\mathrm{C} / \mathrm{S}$, where the generalized facet was Sessions. A Generalizability coefficient (on forwards $\mathrm{G}$ coefficient) of 0.80 is considered an accepted standard for descriptive studies (Volpe et al., 2011), so it was adequate to observe two sessions for each focal student. The results are shown in Table 7.

Table 7 .

Decision Study for Sessions.

\begin{tabular}{cccc}
\hline \multicolumn{3}{c}{ Generalizability Study } \\
\hline $\begin{array}{c}\text { Focal } \\
\text { Student }\end{array}$ & $\begin{array}{c}\text { Number of } \\
\text { Sessions }\end{array}$ & $\begin{array}{c}\text { G } \\
\text { Relative }\end{array}$ & $\begin{array}{c}\text { G } \\
\text { Absolute }\end{array}$ \\
\hline MVW & 2 & .852 & .852 \\
MVP & 2 & .931 & .931 \\
MRP & 2 & .970 & .970 \\
MRW & 2 & .862 & .862 \\
\hline
\end{tabular}

Note: MVW: Most valued for working. MVP: Most valued for playing. MRP: Most rejected for playing. MRW: Most rejected for working.

\section{Relative frequencies of behaviors}

The analysis of relative frequencies is necessary to establish which ones are relevant as precedent behaviors of possible behavioral patterns. There were two kind of codes that were not selected as precedent behaviors: (1) FNI "Focal student No Interaction", that implies an absence of interaction; and (2) FY - "Focal student Unobservable", which means that focal student can not be coded because is not possible to hear or see him in proper conditions. The relative frequencies of MVT's behaviors are in Figure 1.

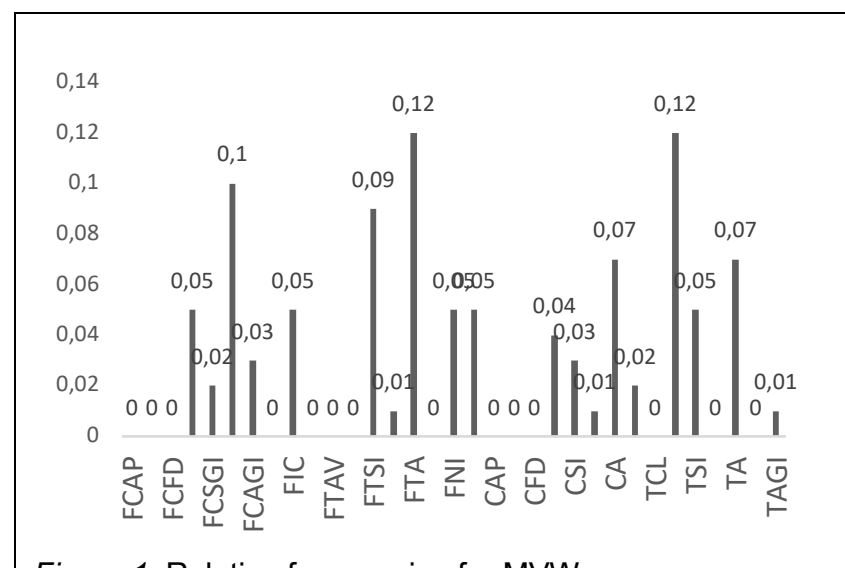

Figure 1. Relative frequencies for MVW.

Those related with MVP are in Figure 2.

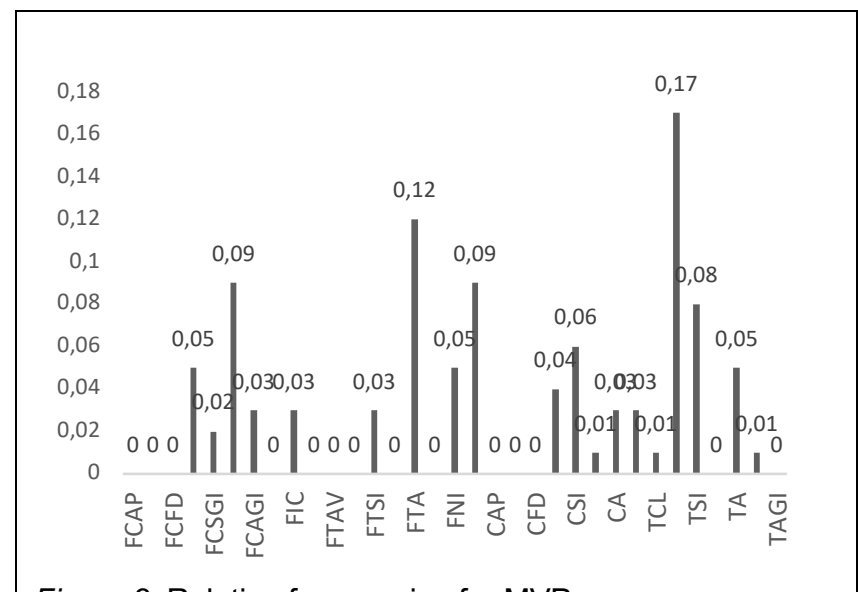

Figure 2. Relative frequencies for MVP. 
The frequencies of MRP are in Figure 3.

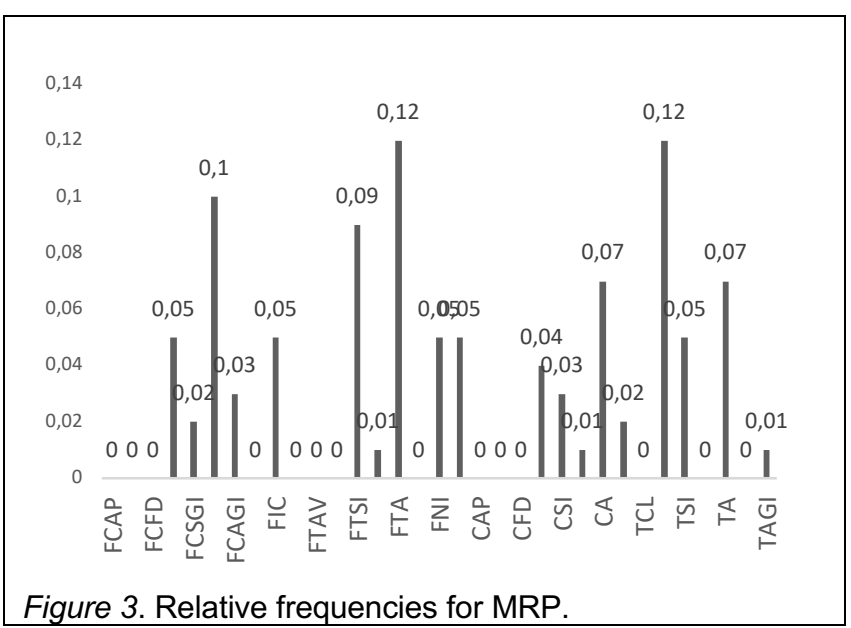

Lastly, those related with MRW are in Figure 4.

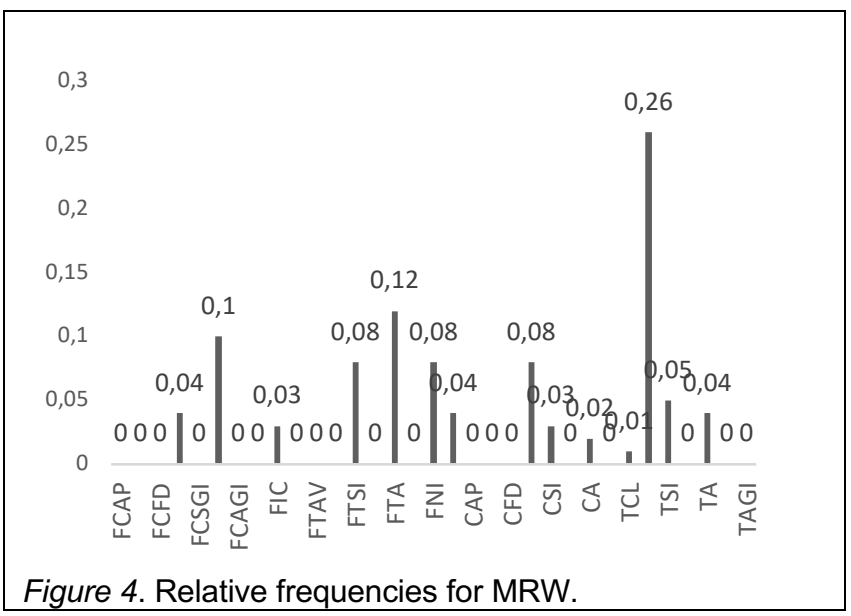

\section{Assessment of the mechanisms that regulate social interaction: effective- ness, correspondence and reciprocity}

\section{Social effectiveness}

The first pattern is "Focal Student Starts Interaction related with the activity with Teacher (FTSI) - Teacher Answers (TA)" for example, when the focal student asks a question to the instructor about some exercise and the latter answers him in accordance with the interaction subject. It is significant in all sample. The effect sizes are large for MVW, MVP and MRP and medium for MRW.

The second pattern, "Focal Student Starts Interaction related with the activity with the Classmate (FCSI) Classmate Answers (CA)", happens, for example, when the student asks a classmate about an activity and the latter answers him. It is significant in all the focal students. The effect sizes are large for the most valued ones and MRP, but medium for MRW.

The third pattern, "Focal Student Starts Interaction Non-related with the activity with Classmate (FCSGI) Classmate Answers General Interaction (CAGI)", is suitable for situations in which the focal student interacts with the classmate with the aim of discussing aspects that are not related with the class dynamics. It is significant only for the most valued ones and their effect sizes are large.

The fourth pattern, "Collective Interaction of Focal Student (FCI) - Classmate Answers (AC)", implies that

Table 8.

Confirmatory patterns of social effectiveness.

\begin{tabular}{|c|c|c|c|c|c|c|c|c|c|c|c|c|c|c|c|c|}
\hline \multirow{2}{*}{$\begin{array}{l}\text { Focal } \\
\text { Student }\end{array}$} & \multicolumn{4}{|c|}{ Pattern 1} & \multicolumn{4}{|c|}{ Pattern 2} & \multicolumn{4}{|c|}{ Pattern 3} & \multicolumn{4}{|c|}{ Pattern 4} \\
\hline & $\mathbf{F}$ & $\mathbf{R}$ & $d$ & $\mathbf{Q}$ & $\mathbf{F}$ & $\mathbf{R}$ & $d$ & $\mathbf{Q}$ & $\mathbf{F}$ & $\mathbf{R}$ & $d$ & $\mathbf{Q}$ & $\mathbf{F}$ & $\mathbf{R}$ & $d$ & $\mathbf{Q}$ \\
\hline MVP & $8 / 24$ & 9.06 & 0.89 & .94 & $8 / 16$ & 7.97 & 0.81 & .92 & $9 / 13$ & 16.16 & 1.43 & 0.99 & $0 / 16$ & N.S. & 0.42 & -1 \\
\hline MRW & $11 / 28$ & 6.13 & 0.62 & .80 & $4 / 13$ & 5.15 & 0.59 & .86 & N.A. & N.A & N.A & N.A & $3 / 13$ & 4.15 & 0.61 & 0.83 \\
\hline
\end{tabular}

Note. MVW: Most valued for working. MVP: Most valued for playing. MRP: Most rejected for playing. MRW: Most rejected for working. F: Frequency. R: Adjusted Residual. d: Cohen's D for effect size. Q: Q of Yule. N.S.: No significant. N.A: do not apply. 
the focal student explains a topic to the classmates and they answer him. It is significant only for the most rejected for working and the effect size is considered medium. Results are shown in Table 8 .

\section{Patterns of absence of social effective- ness}

The adaptation of social interaction is also revealed when the pattern that indicates the mechanism does not take place.

The fifth pattern, "Focal Student Starts Interaction related with the activity with the Classmate (FCSI) - Focal Student Starts Interaction related with the activity with the Classmate (FCSI)", confirms absence of social effectiveness in the focal students MVP and MRW, although the frequency of appearance is low for both. The effect size is considered large for MVP and medium for MRW (Table 9).

Table 9.

Pattern of absence of social effectiveness.

\begin{tabular}{ccccc}
\hline $\begin{array}{c}\text { Focal } \\
\text { Student }\end{array}$ & Frequency & $\begin{array}{c}\text { Adjusted } \\
\text { Residual }\end{array}$ & $\boldsymbol{d}$ & $\begin{array}{c}\text { Q of } \\
\text { Yule }\end{array}$ \\
\hline MVP & $4 / 28$ & 2.11 & .81 & .52 \\
MRW & $4 / 24$ & 3.37 & .59 & .71 \\
\hline
\end{tabular}

Note. MVP: Most valued for playing. MRW: Most rejected for working. $\boldsymbol{d}$ : Cohen's D for effect size.

The sixth pattern is "Focal Student Starts Interaction Non-related with the activity with Classmate (FCSGI) Focal Student Starts Interaction with Classmate Non-related with the activity (FCSGI)", and it can be understood as an attempt from the focal student of establishing an interaction non-related with the task with his classmate, followed by a new attempt caused by an absence of answers. It is significant in the focal student MVW, but with a low frequency, so it should be taken with caution. The effect size is large (Table 6).

The seventh pattern is "Focal Student Starts Interaction related with the activity with teacher (FTSI) - Focal Student Starts Interaction related with the activity with teacher (FTSI)", for example, when the student asks the teacher about the activity that he is doing and, if he does not obtain any answer, tries again. It is only significant for the student MVW with medium effect size (Table 10).

Table 10.

Patterns of absence of social effectiveness for the most valued for working.

\begin{tabular}{lccc}
\hline $\begin{array}{l}\text { Focal } \\
\text { student }\end{array}$ & & Pattern $\mathbf{6}$ & Pattern 7 \\
\hline & F & $1 / 9$ & $8 / 43$ \\
MVW & $\mathbf{R}$ & 2.00 & 2.18 \\
& $\boldsymbol{d}$ & 1.26 & 0,74 \\
& $\mathbf{Q}$ & .75 & .43 \\
\hline
\end{tabular}

Note. MVW: Most valued for working. F: Frequency. R: Adjusted Residual. Q: Q of Yule. d: Cohen's D for effect size.

\section{Social Correspondence}

This mechanism determines if the environment is able to produce answers, in terms of interaction, in the focal students of this study. The results are shown in Table 11.

The eighth pattern, "Teacher Starts Interaction related with the activity (TSI) - Focal Student Answers Teacher (FTA)", for example, when the teacher explains an activity and the student asks him about it. It is significant in all the sample with medium effect sizes.

The ninth pattern, "Exposition in Group by Teacher (TEG) - Focal Student Answers Teacher (FTA)", is significant in all focal students, and it implies that the teacher is explaining some topic and the focal student pays attention or answers following the exposition topic. The effect size is medium in all the cases.

The tenth pattern is "Classmate Starts Interaction related with the activity (CSI) - Focal Student Answers Classmate ( $F C A$ )", for example, when the classmate asks focal student what option did he choose in the exercise, and the focal student answers him. It is significant in all the observed students. The effect sizes are large for the most valued ones, although they are medium for the most rejected ones. 
Table 11.

Confirmatory patterns of social effectiveness.

\begin{tabular}{|c|c|c|c|c|c|c|c|c|c|c|c|c|c|c|c|c|}
\hline \multirow{2}{*}{$\begin{array}{l}\text { Focal } \\
\text { Student }\end{array}$} & \multicolumn{4}{|c|}{ Pattern 8} & \multicolumn{4}{|c|}{ Pattern 9} & \multicolumn{4}{|c|}{ Pattern 10} & \multicolumn{4}{|c|}{ Pattern 11} \\
\hline & $\mathbf{F}$ & $\mathbf{R}$ & $d$ & $\mathbf{Q}$ & $\mathbf{F}$ & $\mathbf{R}$ & $d$ & $\mathbf{Q}$ & $\mathbf{F}$ & $\mathbf{R}$ & $d$ & $\mathbf{Q}$ & $\mathbf{F}$ & $\mathbf{R}$ & $d$ & $\mathbf{Q}$ \\
\hline MVP & $20 / 62$ & 7.37 & .71 & .81 & $23 / 62$ & 4.64 & .69 & .57 & $18 / 45$ & 9.80 & .93 & .91 & $15 / 45$ & 10.07 & .91 & .94 \\
\hline MRW & $17 / 76$ & 7.91 & .71 & .86 & $36 / 76$ & 4.65 & .72 & .51 & $6 / 64$ & 3.32 & .68 & .66 & $32 / 64$ & 12.69 & 1.06 & .93 \\
\hline
\end{tabular}

Note. MVW: Most valued for working. MVP: Most valued for playing. MRP: Most rejected for playing. MRW: Most rejected for working. F: Frequency. R: Adjusted Residual. Q: Q of Yule. d: Cohen's D for effect size.

The eleventh pattern, "Collective Interaction by Classmate (CCI) - Focal Student Answers Classmate (FCA)" implies that, when a classmate does an exposition, the focal student pays attention or answers to him/her following the interaction topic. It is significant for all participants and the effect size is medium for MVT and large for MVP, MRP and MRW.

\section{Patterns of absence of social corre- spondence}

The twelfth pattern, "Classmate Starts Interaction related with the activity (CSI) - Classmate Starts Interaction related with the activity (CSI)", denotes absence of mechanism. For example, the classmate asks the focal student about the activity that they are doing and, without an answer, the classmate tries asking again. It is significant in the most rejected ones, where the effect sizes are medium.

The thirteenth pattern, "Teacher Starts Interaction related with the activity (TSI) - Teacher Starts Interaction related with the activity (TSI)", is significant for MVW and MRP, coding when the teacher talks to the student about the task that he is doing and reiterates the interaction because he does not obtain any answer. The effect sizes are medium.

The fourteenth pattern is "Exposition in Group by Teacher (TEG) - Focal Student No interaction (FNI)", being representative situations in which the teacher is explaining and the focal student is focused in the task or, simply, does not show interaction behaviors. This pattern is significant in the four focal students, with medium effect sizes.

The fifteenth pattern is "Collective Interaction by Classmate (CCI) - Focal Student No Interaction (FNI)" and takes place, for example, when a classmate is explaining to his peers some interesting theme and the focal student is deep into another task. Again, it is a significant pattern only for the MVW student and the effect size is considered medium. The results are shown in Table 12.

Table 12.

Patterns of absence of social correspondence.

\begin{tabular}{lrrrrrrrrrrrrrrrr}
\hline Focal & \multicolumn{4}{c}{ Pattern 12 } & \multicolumn{1}{c}{ Pattern 13 } & \multicolumn{4}{c}{ Pattern 14 } & \multicolumn{4}{c}{ Pattern 15 } \\
\cline { 2 - 14 } Student & $\mathbf{F}$ & $\mathbf{R}$ & $\boldsymbol{d}$ & $\mathbf{Q}$ & $\mathbf{F}$ & $\mathbf{R}$ & $\boldsymbol{d}$ & $\mathbf{Q}$ & $\mathbf{F}$ & $\mathbf{R}$ & $\boldsymbol{d}$ & $\mathbf{Q}$ & $\mathbf{F}$ & $\mathbf{R}$ & $\boldsymbol{d}$ & $\mathbf{Q}$ \\
\hline MVW & $0 / 16$ & N.S & .85 & -1 & $3 / 22$ & 1.99 & .65 & .55 & $6 / 23$ & 2.23 & .71 & .49 & $3 / 23$ & 2.09 & .76 & .57 \\
MVP & $2 / 32$ & N.S & .93 & 0 & $1 / 42$ & N.S & .71 & -.59 & $10 / 27$ & 2.94 & .69 & .53 & $1 / 27$ & N.S. & .90 & -.08 \\
MRP & $4 / 26$ & 3.04 & .69 & .67 & $5 / 35$ & 2.42 & .68 & .53 & $18 / 46$ & 2.56 & .71 & .38 & $2 / 44$ & N.S. & .87 & -.19 \\
MRW & $3 / 18$ & 3.58 & .68 & .78 & $0 / 29$ & N.S & .71 & -1 & $22 / 50$ & 3.12 & .72 & .43 & $5 / 50$ & N.S. & .28 & .11 \\
\hline
\end{tabular}

Note. MVW: Most valued for working. MVP: Most valued for playing. MRP: Most rejected for playing. MRW: Most rejected for working. F: Frequency. R: Adjusted Residual. Q: Q of Yule. N.S.: No significant. d: Cohen's D for effect size. 
Table 13.

Patterns of presence of social reciprocity.

\begin{tabular}{ccccccccc}
\hline & \multicolumn{7}{c}{ Lag 1 } & \multicolumn{7}{c}{ Lag 2 } \\
\hline Focal student & Frequency & Adjusted Residual & $\boldsymbol{d}$ & $\mathbf{Q}$ & Frequency & Adjusted Residual & $\boldsymbol{d}$ & $\mathbf{Q}$ \\
\hline MRW & $12 / 28$ & 5.14 & .65 & .73 & $24 / 76$ & 5.59 & .55 & .63 \\
\hline
\end{tabular}

Note. MRW: Most rejected for working. Q: Q of Yule. N.S: No significant. d: Cohen's D for effect size.

\section{Social reciprocity}

In this section the aim is to verify an interaction's continuity between the focal student and his environment, there is an analysis of both the first lag and the second lag.

The sixteenth pattern, "First Focal Student Answer (FA) / Teacher Answers (TA) Lag 1/ Focal Student Answers (FA) Lag 2" alludes to when a focal student's answer is related with the activity, it is followed by a teacher's answer, and this last one is followed again by a new answer of the focal student. Only the student MRW keeps continuity in the exchange of interactions with the teacher. The effect size is medium (Table 13).

No significant behavioral patterns indicators of absence of social reciprocity were obtained.

\section{Discussion}

The aim of this study was to confirm if there were differences in the mechanisms of social interaction between the most valued and the most rejected students by their peers in a group of high ability students. It was expected to find significant behavioral patterns indicators of presence of social effectiveness, correspondence and reciprocity (Santoyo, 1996, 2006) and no significant patterns indicators of absence on the most valued students (in comparison with the most rejected ones). According to our results, it is not possible to confirm the presence of differences. In general terms, appropriate and adaptive behavioral patterns were detected in the four focal students.
Through the mechanisms identified by Santoyo (1996, 2006), in terms of social effectiveness, all the participants have the ability of producing a reaction in their environment, when the context is related with the task. Exclusively, the most valued ones also showed confirmatory patterns relative to interactive contents non-related with the task with their peers. Nevertheless, the students MVW, MVP and MRW, occasionally do not get a reply from their classmates and they persevere in their starts of interaction. However, this has to be taken with caution, because the frequency of the patterns is low and a small representative sample of behaviors could be overvalued. It is necessary to observe longer to confirm if these students have any problem in their social effectiveness and, given the circumstances, to intervene.

With regard to social correspondence, all the participants show the ability for replying to the environment when it is about a context referred to the task, reinforcing the initiatives of the teacher and classmates who are trying to interact. Despite this, all the participants do not interact when the teacher makes and exposition to the group. This pattern does not refer to negative behaviors but that the students are focused on their activities. There are also indicators of absence of mechanism both for the MVW student and the MRW. However, the low frequency of those patterns may indicate that they are not necessarily a representative sample of behaviors. Moreover, these students present other patterns in which they reply the interaction initiatives with a higher frequency of appearance. Although is necessary to pay attention to those unfavorable patterns as in the previous case.

In the case of social reciprocity, the student MRW is the only one that presents a confirmatory pattern which 
implies that he gets to keep a dyadic and equitable interaction related with the task with the teachers.

The results of this study do not let us conclude that there are differences in the mechanisms that regulate interaction between the most valued and the most rejected students. However, more general interactions related with the activity are detected among the most valued ones. The lack of reciprocity is also surprising, which occurs in just one of the participants and it is not related with the classmates. A possible explanation could be related with the characteristics of the program and the organization of the sessions. Although the students are allowed to interact with their classmates, the structured character of the activities does not foster long conversations or the continuation of interactions between two or more children. Therefore, it would be desirable to observe these students in an open and ludic context or in a less structured environment to analyze if the same results would be obtained.

Appropriate behavioral patterns were detected in all participants. These findings are in line with those studies which supported the gifted students have an appropriate socio-emotional adjustment (Borges et al., 2011; Hoogeveen et al., 2012; Jen et al., 2017; López \& Sotillo, 2009; Neihart, 2007; Robinson, 2008) and with those studies where observational methodology was used to analyze the social behavior in special environments (Bokkina, 2016; De Jonge, 2016; Cadenas \& Borges, 2017).

This study is not exempt of limitations which should be considered to understand the results of this study.

In the first place, the characteristics of the program and the group. This program is developed from a preventive perspective, so it is not expected that participants present interaction difficulties with their environment. Secondly, the sessions take place every fifteen days so it may be that the relationships established are not as strong as interpersonal relationships developed in contexts where students share more time together, like in the school. Thus, even though the sociogram showed its utility in analyzing the structures of the groups and identifying the social status of a child (Santoyo, 1994b), perhaps it was not an adequate instrument to select the most valued and most rejected ones in this program. Thirdly, the size of the sample is small, therefore is not possible to generalize the results obtained. Nevertheless, in observational studies the sample tends to be small in comparison with quantitative studies but still offers great information about the behavior of the individual. Finally, the Decision Study for time observation perhaps should be checked in this context while increasing the time of coding. It would be interesting to employ the Decision Study as a first criterion but increasing both time and sessions until achieving the point in which new significant patterns do not appear. Consequently, although the obtained results do not show differences in the mechanisms of the participants, it could be convenient to analyze the instrument in more steady groups.

Most of the works regarding personal and social abilities of children with high intellectual abilities are based on interviews and questionnaires. In the field of social interaction, it has been already pointed out the utility of combining diverse techniques for the identification of social relations in natural settings (see Flores \& Santoyo, 2009). In line with this work, it would be desirable to use more than one source of information when the characteristics of the sample and the scenario allow so. An appropriate way of studying interpersonal relationships in educational environments is to directly see how students behave. For this, it is necessary to adapt a procedure which allows the operativization of behaviors. This represents another perspective in the analysis of the social relations (Flores \& Santoyo, 2009; Santoyo 1994b) and highlights the need of studying social context as a construct for evaluating special environments (Coleman, 2014b).

This work, despite the limitations already mentioned, represents a useful procedure to evaluate not only the social network and relations established within the program, but also to evaluate the aims previously defined in an enrichment program focused on the promotion of the relations with their peers. Additionally, the observational instrument presented on this work, and previously published (Cadenas et al., 2013; Cadenas \& Borges, 2016, 2017), is also useful in the prevention of further problems due to through observation it is possible to detect vulnerabilities and difficulties in the social abilities of some children which may be not evident from an external point of view. Future lines of research should focus first on the 
replication of this study in bigger groups and with more points of observation and in the design of a short version of the instrument that could be used as a preliminary evaluation of the social context within the classroom. This would save time and efforts in the detection of issues susceptible to improve.

\section{References}

Almeida, L. S., Araújo, A. M., Sainz-Gómez, M., \& Prieto, D. (2016). Challenges in the Identification of Giftedness: Issues Related to Psychological Assessment. Anales de Psicología, 32(3), 621-627. https://doi.org/10.6018/analesps.32.3.259311

Anguera, M. T. (1990). Metodología Observacional. [Observational Methodology] In J., Arnau, M. T. Anguera, \& J. Gómez Benito. Metodología de la investigación en ciencias del comportamiento [Methodology of Behavior Sciences Research] (pp. 125-236). Murcia, Spain: Universidad de Murcia.

Anguera, M. T., Blanco, A., \& Losada, J. L. (2001). Diseños observacionales, cuestión clave en el proceso de la metodología observacional. [Observational Desgins, Key Question in Observational Methodology]. Metodología de las Ciencias del Comportamiento, 3(2), 135-160.

Anguera, M. T. \& Hernández-Mendo, A. (2013). La metodología observacional en el ámbito del deporte. [Observational Methodology in Sport Field]. Revista de Ciencias del Deporte, 9(3), 135-160.

Bakeman, R. \& Gottman, J. M. (1989). Observación de la interacción: introducción al análisis secuencial. [Observation of Interaction: Sequential Analysis Introduction]. Madrid, Spain: Ediciones Morata, S.A

Bakeman R. \& Quera V. (1995). Analyzing Interaction. Sequential Analysis with SDIS and GSEQ. New York, NY: Cambridge University Press.
Bakeman, R. \& Quera, V. (1996). Análisis de la interacción: Análisis secuencial con SDIS y GSEQ. [Analyzing interaction: Sequential Analysis with SDIS and GSEQ]. Madrid, Spain: Ra-Ma.

Behar, J. \& Riba, C. (1993). Sesgos del observador y de la observación. [Observer and Observation Bias]. In M.T. Anguera (Ed.), Metodología observacional en la investigación psicológica (Vol.2, Fundamentación [Observational Methodology in the Psychological Research]. (pp. 11-148). Barcelona, Spain: PPU.

Blanco-Villaseñor, A. (1991). La teoría de la generalizabilidad aplicada a diseños observacionales [The Generalizability Theory Applied to Observational Designs]. Revista Mexicana de Análisis de la Conducta, 17(3), 23-63. https://doi.org/10.5514/rmac.v 17.i3.23338

Bokkina, E. I. (2016). Social Interaction of the Gifted Children in a Heterogeneous Environment. (Master's Thesis). Nihmegen: Radboud University.

Borges, A. \& Hernández-Jorge, C. (2006). La superdotación intelectual: algo más que un privilegio. [Intellectual Giftedness: Something more Tan a Privilege]. Acta Científica y Tecnológica, 10, 28-33.

Borges, A., Hernández-Jorge, C., \& Rodríguez-Naveiras, E. (2011). Evidencias contra el mito de la inadaptación de las personas con altas capacidades intelectuales. [Evidences against the Maladjustment Myth of High Ability People]. Psicothema, 23(3), 362-367.

Briesch, A. M., Swaminathan, H., Welsh, M., \& Chafouleas, S. M. (2014). Generalizability Theory: A Practical Guide to Study Design, Implementation and Interpretation. Journal of School Psychology, 52, 13-35. https://doi.org/10.1016/j.jsp.2013.11.00 8

Cadenas, M. \& Borges, Á. (2016). Procedimientos e instrumentos de evaluación para el estudio de la interacción social. Análisis de la interacción en aula 
[Procedures and Assessment Tools for the Study of Social Interaction. Analysis of Interaction in the Classroom]. Saarbrücken: eae-Editorial Académica Española.

Cadenas, M. \& Borges, A. (2017). The Assessment of Change in Social Interaction through Observation. Acción Psicológica, 14(1), 121-136. https://doi.org/10.5944/ap.14.1

Cadenas, M., Borges, A., \& Falcón, C. (2013). Análisis y depuración de un instrumento para la observación de la interacción dentro del aula [Analysis and Refinement of an Instrument for Observation of Interaction inside the Classroom]. Revista de Investigación y Divulgación en Psicología y Logopedia, $3(2), 18-23$.

Cadenas, M., Rodríguez, M., \& Díaz, M. (2012). Los equipos de entrenamiento: una muestra para el estudio de los sesgos en la fiabilidad entre parejas de observadores [The Training Teams: A Sample for the Study of Bias between Pairs of Observers]. Revista de Investigación y Divulgación en Psicología y Logopedia, 2(2), 41-46.

Cairns, R. B. (1979). The analysis of Social Interactions: Methods, Issues, and Illustrations. Hillsdale, N.J.: Lawrence Erlbaum Associates.

Calero, M. D., García-Martin, B. M., \& Robles, M. A. (2011). Learning potential in high IQ children: The contribution of dynamic assessment to the identification of gifted children. Learning and Individual Differences, 21, 176-181. https://doi.org/10.1016/j. lindif.2010.11.025

Castellano, J., Hernández-Mendo, A., Gómez, P., Fontetxa, E., \& Bueno, I. (2000). Sistema de codificación y análisis de la calidad del dato en el fútbol de rendimiento [System of coding and analysis of the data's quality in performance football]- Psicothema, 12(4), 319-333.

Cavilla, D. (2017). Observation and Analysis of Three Gifted Underachievers in an Underserved, Urban
High School Setting. Gifted Education International, 33(1), 62-75. https://doi.org/10.1177/ 0261429414568181

Clinkenbeard, P. R. (2012). Motivation and Gifted Students: Implications of Theory and Research. Psychology in the Schools, 49(7), 622-630. https://doi.org/10.1002/pits.21628

Cohen, J. (1960). A Coefficient of Agreement for Nominal Scales. Educational and Psychological Measurement, 20, 37-46.

Cohen, J. (1988). Statistical Power Analysis for the Behavioral Sciences. Hillsdale, NJ: Laurence Erlbaum Associates.

Coleman, L. J. (2014a). The Power of Specialized Educational Environments in the Development of Giftedness: The Need for Research on Social Context. Journal for the Education of the Gifted, 37(1), 70-80. https://doi.org/10.1177/0162353214521520

Coleman, L. (2014b). The Cognitive Map of a Master Teacher Conducting Discussions With Gifted Students. Journal for the Education of the Gifted, 37(1), 40-55. https://doi.org/10.1177/0162353214 521493

Coleman, L. \& Cross, T. (2000). Socio-Emotional Development and the Personal Experience of Giftedness. En, K. A. Heller, F. J. Monks, R. J. Sternberg, y R. F. Subotnik (Eds.), International handbook of giftedness and talent (pp. 203-213). Oxford, UK: Elsevier.

Cronbach, L. J., Gleser, G. C., Nanda, H., \& Rajaratnam, N. (1972). The Dependability of Behavioral Measurements: Theory of Generalizability for Scores and Profiles. Nueva York, NY: Wiley.

De Jonge, M. (2016). Social interaction in enrichment classes: differences between popular and rejected gifted children (Master's Thesis). Radboud University, Nijmegen. 
Flores, N. \& Santoyo, C. (2009). Estabilidad y cambio de las relaciones sociales entre niños: análisis de mecanismos funcionales [Stability and Change of Social Relationships in Children: Functional Mechanisms Analysis]. Revista Mexicana de Análisis de Conducta, 3(1), 59-74.

Gabín, B., Camerino, O., Anguera, M. T., \& Castañer, M. (2012). Lince: Multiplatform Sport Analysis Software. Procedia-Social and Behavioral Sciences, 46, 4692- 4694.

Gagné, F. (2015). Academic Talent Development Programs: A Best Practices Model. Asia Pacific Education Review, 16, 281-295. https://doi.org/10. 1007/s12564-015-9366-9

Graffam, B. (2006). A Case Study of Teachers of Gifted Learners: Moving From Prescribed Practice to Described Practitioners. Gifted Child Quarterly, 50(2), 119-131.

Hernández-Mendo, A., Ramos-Pérez, F., \& Pastrana, J. L. (2012). SAGT: Programa informático para análisis de Teoría de la Generalizabilidad [SAGT: Computer Program for Generalizability Theory analysis]. Las Palmas de Gran Canaria, Spain: Safe Creative.

Hoogeveen, L., van Hell, J. G., \& Verhoeven, L. (2012). Social-emotional Characteristics of Gifted Accelerated and Non-Accelerated Students in the Netherlands. British Journal of Educational Psychology, 82, 585-605. https://doi.org/10.1111/j. 2044-8279.2011.02047.x

Jen, E., Gentry, M., \& Moon, S. M. (2017). High-Ability Students' Perspectives on an Affective Curriculum in a Diverse University-Based Summer Residential Enrichment Program. Gifted Child Quarterly, 61(4), 328-342. https://doi.org/10.1177/00169861 7722839

Lee, S., Olszewski-Kubilius, P., \& Thomson, D. (2012). Academically Gifted Students' Perceived Interpersonal Competence and Peer Relationships. Gifted
Child Quarterly, 56(2), 90-104. https://doi.org/10. $1177 / 0016986212442568$

Little, C. A. (2012). Curriculum as Motivation for Gifted Students. Psychology in the Schools, 49(7), 695705. https://doi.org/10.1002/pits.21621

Lloyd, B. P., Kennedy, C. H., \& Yoder, P. J. (2013). Quantifying Contingent Relations from Direct Observation Data: Transitional Probability Comparison versus Yule's Q. Journal of Applied Behavior Analysis, 46(2), 479-497. https://doi.org/10.1002/ jaba.45

López, V. \& Sotillo, M. (2009). Giftedness and Social Adjustment: Evidence Supporting the Resilience Approach in Spanish-Speaking Children and Adolescents. High Ability Studies, 20, 39-53. https://doi.org/10.1080/13598130902860739

McCoach, B., Rambo, K. E., \& Welsh, M. (2013). Assessing the Growth of the Gifted Students. Gifted Child Quarterly, 57(1), 56-67. https://doi.org/10. $1177 / 0016986212463873$

Mills, C. J. (2003). Characteristics of Effective Teachers of Gifted Students: Teacher Background and Personality Styles of Students. Gifted Child Quarterly, 47(4), 272-281. https://doi.org/10.1177/0016986 20304700404

Neihart, M. (2007). The Socioaffective Impact of Acceleration and Ability Grouping: Recommendations for Best Practice. Gifted Child Quarterly, 51, 330-341. https://doi.org/10.1177/00169862073063 19

Netz, H. (2014). Gifted Conversations: Discursive Patterns in Gifted Classes. Gifted Child Quarterly, 58(2), 149-163. https://doi.org/10.1177/00169862 14523312

Plucker, J. A. \& Callahan, C. M. (2014). Research on Giftedness and Gifted Education: Status of the Field and Considerations for the Future. Excep- 
tional Children, 80(4), 390-406. https://doi.org/ $10.1177 / 0014402914527244$

Reis, S. \& Renzulli, J. (2010). Is there is Still a Need for Gifted Education? An Examination of Current Research. Learning and Individual Differences, 20, 308-317. https://doi.org/10.1016/j.lindif.2009. 10.012

Renzulli, J. S. \& Reis, S. M. (2003). The Schoolwide Enrichment Model: Developing Creative and Productive Giftedness. In N. Colangelo \& G. A. Davis (Eds.), Handbook of Gifted Education (pp. 184203). Boston, MA: Allyn and Bacon.

Robinson, N. M. (2008). The Social World of Gifted Children and Youth. In S. I. Pfeiffer (Ed.), Handbook of Giftedness in Children: Psychoeducational Theory, Research, and Best Practices (pp. 33-51). New York, NY: Springer.

Rodríguez, A. \& Morera, M. D. (2001). El sociograma: estudio de las relaciones informales en las organizaciones [The Sociogram: Informal Relationships Study in Organizations]. Madrid, Spain: Pirámide.

Rodríguez-Dorta, M. \& Borges, A. (2016). Optimización y eficiencia en el análisis de datos en metodología observacional [Data Analysis Optimization and Efficiency in Observational Methodology]. Revista Electrónica de Metodología Aplicada, 21(1), $1-15$.

Rodríguez-Dorta, M. \& Borges, A. (2017). Behavioral Patterns in Special Education. Good Teaching Practices. Frontiers in Psychology, 8(631), 1-14. https://doi.org/10.3389/fpsyg.2017.00631

Rodríguez-Naveiras, E. (2011). PROFUNDO: Un instrumento para la evaluación de proceso de un programa de altas capacidades [PROFUNDO: An Instrument for Process Assessment of a High Ability Program]. (Doctoral Thesis), Universidad de La Laguna, La Laguna.
Santoyo, C. (1994a). Contexto e interacción social: bases conceptuales y metodológicas [Context and Social Interaction: Conceptual and Methodological Basics]. Barcelona, Spain: Promociones y Publicaciones Universitarias.

Santoyo, C. (1994b). Sociometría conductual: el diseño de mapas socioconductuales. [Behavioral Sociometry: The Design of Sociobehavioral Maps]. Revista Mexicana de Análisis de Conducta, 20(2), 183205.

Santoyo, C. (1996). Behavioral Assessment of Social Interactions in Natural Settings. European Journal of Psychological Assessment, 12(2), 124-131.

Santoyo, C. (2006). La ecología social de la cotidianeidad en la escuela: Redes sociales y mecanismos funcionales [Social Ecology of Everyday Nature at School: Social Networks and Functional Mechanisms]. In C. Santoyo y C. Espinosa (Eds.), Desarrollo e interacción social: Teoría y métodos de investigación en contexto [Development and Social Interaction: Theory and Researching Methods in Context] (pp.113-150). México: UNAM/ CONACyT.

Sternberg, R. J. (2000). Patterns of Giftedness: A Triarchic Analysis. Roeper Review, 22, 231-235.

Sternberg, R. J. (2010). Assessment of Gifted Students for Identification Purposes: New techniques for a new Millennium. Learning and Individual Differences, 20, 327-336. https://doi.org/10.1016/j.lindif.2009.08.003

Stoeger, H. \& Ziegler, A. (2010). Do Pupils with Differing Cognitive Abilities Benefit Similarly from a Self- Regulated Learning Training Program? Gifted Education International, 26, 110123. https://doi.org/10.1177/026142941002600113

Subotnik, R. F., Olszewski-Kubilius, P., \& Worrel, F. C. (2011). Rethinking Giftedness and Gifted Education: A Proposed Direction Forward Based on Psychological Science. Psychological Science in the 
Public Interest, 12(1), 3-54. https://doi.org/ $10.1177 / 1529100611418056$

Tannenbaum, A. J. (1986). Giftedness: A Psychosocial Approach. In R. J. Sternberg y J. E. Davidson (Eds.), Conceptions of giftedness (pp.21-52). New York, NY: Cambridge University Press.

VanTassel-Baska, J. (2009). Affective Curriculum and Instruction for Gifted Learners. In J. VanTasselBaska, T. L. Cross, \& F. R. Olenchak (Ed.), SocialEmotional Curriculum, with Gifted and Talented Students (pp. 113-132). Texas: Prufrock Press.

Volpe, R. J., Briesch, A. M., \& Gadow, K. D. (2011). The Efficiency of Behavior Rating Scales to Assess Inattentive-Overactive and Oppositional-Defiant Behaviors: Applying Generalizability Theory to Streamline Assessment. Journal of School Psychology, 49,131-155.

Westberg, K., Archambault, F. X., Dobyns, S. M., \& Salvin, T. J. (1993). The Classroom Practices Observation Study. Journal for the Education of the Gifted, 16(2), 120-146. https://doi.org/10.1177/ 016235329301600204

Ziegler, A. \& Phillipson, S. N. (2012). Towards a Systemic Theory of Gifted Education. High Ability Studies, 23(1), 3-30. https://doi.org/10.1080/ 13598139.2012.679085 